\title{
MAKING A CASE FOR HCI: COMPARING MATERIALS FOR CASE-BASED TEACHING
}

\author{
Jacob Somervell', C. M. Chewar ${ }^{2}$, D. Scott McCrickard ${ }^{3}$
}

\begin{abstract}
This paper investigates case-based methods for bridging the conflicting goals of providing both topic coverage and practical experience in teaching humancomputer interaction (HCI). Case-based methods rely on design, development, and testing material for existing or on-going projects to provide details on difficult decisions and solutions in the interface creation process. Cases are touted as alternatives to real experience (immensely important in $\mathrm{HCI}$ courses) and provide rich environments for computer science instruction. We evaluate benefits and limitations of five types of case materials--contemporary articles, professionally prepared cases, familiar interfaces, ongoing development projects, and incomplete information (jigsaw)-to probe how they should be structured and approached by an HCI instructor. Through an experience that assessed case-based activities in an undergraduate HCI course, we determined tradeoffs relating to student participation, preparation characteristics, and short-and long-term learning outcomes. Professionally prepared case materials provided a sense of comfort in preparation, but were surpassed by familiar interfaces in terms of performance and post-use feedback, leading to recommendations for case materials development and adoption of case-based learning for HCI. Based on our results, we can make several conclusions that should influence selection and development of materials for casebased pedagogy, and we illustrate the need for structured case creation processes that can be performed conjointly with system development efforts.
\end{abstract}

Index Terms - Cases, human-computer interaction, problembased learning

\section{MOTIVATION FOR CASES IN HCI}

Computer science instructors without any background in human computer interaction (HCI) are often confronted with the challenge of introducing the topic into their curricula in a rigorous, cumulative manner. Although the typical goal of computer science classes is to provide students with a practical skill set, instructors also target development of abstract concepts and appreciation of the scientific method. However, after participating in and analyzing HCI education as a student, teaching assistant, instructor, and educational researcher since 1992, we observe that HCI is often integrated into a curriculum as loosely connected topicsprompting our search for an improved educational strategy.

Although topics included in typical courses represent important directions within HCI, they are often presented disjoint from any design process. For example, if the HC1 topics and learning objectives listed in the Computing Curricula 2001 are structured into a lesson plan and semester design project, students are likely to gain little appreciation for how they connect into a coherent and complete collection of approaches that can be applied to any problem in the field. There should be common tools and methods that are revisited throughout the presentation of disparate topics, providing opportunities for mastery of methods. Just as every good computer science student graduates with an understanding of topics like induction, tractability, deadlock, and polymorphism, students who have completed an HCI course should emerge with a similar, enduring skill set that is applicable within computer science professions. While broader research work in $\mathrm{HCI}$ attempts to collect such methods and provide a more scientific basis for the field, we are looking for a complementary educational approach. This approach would facilitate instruction that engages students and helps them compare alternate approaches, connect abstract theories with practical applications, and make engineering decisions.

Typically, HCI dasses use some variation of two general approaches. In one, students are trained to use methods through a "realistic" design experience, tying a software engineering process with overviews of $\mathrm{HCI}$ concepts like support for collaboration, use of metaphors, and usability testing. A problem with this approach is that students are unable to appreciate the depth of the concepts (or practice the methods that relate) because of constraints such as limited time, lack of programming experience, minimal access to clients, and overly simplified requirements. These constraints either compromise realistic approximations necessary for exposure and conceptual mastery of the HCI lesson, or require significant effort to support, thus drawing resources away from learning objectives, but perhaps resulting in interesting interface products. In the second general approach, students are trained deeply on the HCI concepts but presentation of the concepts is often not situated in a practical software engineering lifecycle. In this approach, an instructor may spend several lessons

\footnotetext{
${ }^{1}$ Center for Human Computer Interaction, Virginia Polytechnic Institute and State University, Blacksburg, VA 24061 jsomerve@ vt.edu

${ }^{2}$ Center for Human Computer Interaction, Virginia Polytechnic Institute and State University, Blacksburg, VA 24061 cchewar@vt.edu

${ }^{3}$ Center for Human Computer Interaction, Virginia Polytechnic Institute and State University, Blacksburg, VA 24061 mccricks@cs.vt.edu

0-7803-7961-6/03/\$17.00 @ 2004 IEEE

October 20 - 23, 2004, Savannah, GA
}

$34^{\text {th }}$ ASEE/IEEE Frontiers in Education Conference 
developing student understanding of challenges within a topic (e.g., design of groupware, universal accessibility, or understanding perception), but leave little time to probe connections to student design projects or to relate the concept to other computer science theories, skills, or methods.

Faced with the paradox created by the conflicting goals of providing both topic coverage and practical experience, we considered the case method as an educational approach for HCI. The case method uses discussions framed on case study materials to help students learn and practice key concepts. Users of the case method in similar disciplines tout it as meeting the same objectives that we target-increased student engagement, improved analytical skills and decisionmaking abilities, and enhanced application of concepts to practical problems [4]. Case methods are quite common in business schools (especially with the Harvard method and materials [2]), law education, and design disciplines like architecture. While case methods are not a commonly practiced form of pedagogy in computer science, there are reports of successful uses, such as in teaching discrete event simulation in a way that integrates an industry-based capstone project [8] and in participatory versions of compiler design, operating systems, and computer architecture classes, allowing analysis of complex design tradeoffs [6]. Although cases are used in slightly different ways and formats in each of these other fields, they do have common characteristics.

Like any challenging HCI development project, the professional activities in each of these other disciplines require substantial time and resources - far more than can be approximated in a classroom setting. As a solution, cases provide a rich context in which to test or discuss a concept, an efficient starting point for a realistic, interactive experience. For example, in information systems management classes, cases have been used to present evolving situations that realistically challenge student analysis and decisionmaking from multiple, "cross-sectional" angles of impact [11]. Other benefits in using cases in education are apparent as well, such as how continuous exposure to new cases helps instructors maintain awareness of professional practices [4].

As we assess the adequacy of the case method for HCI education [9], one important specific question is how case materials should be structured, or what cases should even consist of, for computer science students taking an HCI class. Surprisingly, the many material-format alternatives were found to have important differences in terms of student preparation effort, student and instructor case discussion performance, instructor assessments, and general student reaction. We discuss five different case method material formats that we tested, the outcomes observed, and broader conclusions that serve as recommendations for case material preparation and points for HCI instructors - toward the dual goals of topic coverage and practical experience. This effort 0-7803-7961-6/03/\$17.00 @ 2004 IEEE serves as initial work in adapting the case method toward an improved HCI educational approach.

\section{FIVE CASE MATERIAL OPTIONS}

To study different case material options, we took an introductory undergraduate HCI course and modified the existing lecture method to include alternating class meetings that employed the case method (eleven 75-minute class meetings total). Seventeen students participated in this class. Each case discussion class built on previous lectures, focused on essential concepts, and included materials that situated the concepts in professional HCI activities. Case meeting days employed various types of case materials, each with its own strengths and weaknesses. We used contemporary articles, professional cases materials, familiar interfaces, on-going development projects, and an interesting jigsaw approach with current literature. These five types of materials seemed to promise flexibility in covering a variety of topics through case-based teaching approaches.

\section{Contemporary Articles}

Contemporary articles from the current literature in various fields serve as one type of case material. Our particular choice was an article from interactions that described the development and resulting design guidelines for a 3D virtual world [10]. This article served as an interesting topic for the students, creating and sustaining involvement throughout multiple meetings. Any current article could have been chosen, and this type of case material is readily available. The specific purpose of this type of material is to increase the student interest in the topics, through current reports on technological and theoretical advancements. The biggest advantage of this material type comes from the novelty associated with the new interfaces. This sparks student interest and ultimately sustains it through multiple classes when the material is used for more than one topic. A downside comes from the fact that these articles report on incomplete design projects, often only discussing requirements, early design decisions, and prototypes, limiting the topic applicability.

\section{Professional Case Materials}

Professional case materials can be found in the Usability Case Studies (UCS) library (http://ucs.cs.vt.edu). This is an online tool, prepared by experts, that provides extensive materials on several complete design projects, including Garden.com, a failed internet company from the mid to late 1990's. This rich set of information provides virtually endless opportunities for use in case-based discussions. One strength of this type of case material is the completeness of topics related to the entire design process, from requirements gathering to summative evaluation and testing. Students can relate concepts to all parts of the system development

October 20 - 23, 2004, Savannah, GA 
lifecycle, seeing each step and associated documentation, thereby getting a complete view of the project and impact of design decisions. Drawbacks to this material include the sheer volume of information present-a factor exacerbated by lack of search functionality or ability to reduce content to manageable pieces.

\section{Familiar Interfaces}

Familiar interfaces that can be integrated in the case method are also abundant and easy to find. We chose simple drawing programs like MS Paint and GIMP for our course. Other popular interfaces include chat interfaces (AIM, ICQ), email programs (Eudora, MS Outlook), web browsers (Netscape, Mozilla), word processors (MS Word, WordPerfect), and myriad others. The advantage of using these interfaces as case material is the instant familiarity almost all students will have with them. A downside to this type of material is the boredom factor that students might experience with these familiar interfaces. There are ways to get around that, particularly by assigning activities and tasks that involve changing the interface or using it in a new way.

\section{On-going Development Efforts}

On-going development efforts in the local department or college supply other case study materials. Especially effective are the instructor's own projects, which could be used as examples of interfaces. In this instance, the instructor was involved in developing and testing large screen information exhibits, and used one such effort [3] as case material. Because they are mostly incomplete themselves, they allow the students to perform realistic analysis and evaluation. Furthermore, the instructor is already familiar with the problem domain and the important constraints related to the case material. Another advantage of this case material is that these projects are typically cutting-edge, pushing the envelope on development and creativity in the field, increasing student interest in the topics. A downside to this approach stems from the incomplete nature of the material; often there is very little, if any documentation for students to read in preparation for a case discussion. This puts the extra burden on the instructor to provide necessary background so that students understand and appreciate the case topics.

\section{Jigsaw}

One final category of case material involves an intentionally incomplete distribution of a body of information-a jigsaw. In this case method, the discussion facilitates group interaction to piece together the facts for analysis or decision-making [5]. To create the complementary material, academic papers or lists of design guidelines that present well-sectioned discussions of results and conclusions are ideal. In this instance, we used an article on involving users in the design process [12]. Although students may be given 0-7803-7961-6/03/\$17.00 @ 2004 IEEE some common material for preparation, the jigsaw material is distributed as a small piece to each member of the class. The activity then requires the students to understand their piece and use it to contribute to the discussion, toward the goal of assembling the pieces in a larger context. The incomplete nature of the assigned material can have positive and negative effects. Having a unique, self-contained part of a larger argument may encourage all students to participate in discussion and debate. However, without the benefit of "the big picture," many students are uncomfortable, requiring masterful facilitation techniques within the discussion group.

The overall goals of our introductory HCI course are to teach students the concepts related to the interaction between humans and computers, focusing on the necessity of including a usability engineering aspect in a development project. Lectures are typically aumented with a semester long project for students to demonstrate understanding of the ideas and gain practical experience. At a finer level, students should understand the process involved in creating useful, usable software; starting with requirements gathering and moving through design, prototyping, testing, and iterating the cycle at each point. We used the case based approach for teaching these concepts, relying on the five case material types for providing appropriate content.

\section{RESULTS}

To gain a better understanding about how materials could be used to support case method teaching of Human-Computer Interaction, we considered several measures of material utility for each case session used in the modified course. Each material type was employed at least twice, except the jigsaw type, and with two different case discussion methods (e.g., a decision making process, a review of case history, or a problem-solving activity). Some measures came from student reactions and student performance-student-related outcomes; others came from our reflections and experienceinstructor factors. Specific results are discussed in the following sections and summarized in Table 1, with each measure on the left-hand side and material type along the top.

\section{Student-related Outcomes}

In each case method class period, in-class measures were taken to assess the characteristics of the material for presenting a given topic, specifically capturing how well students were able and willing to understand key concepts and participate in related discussion. In addition to the inclass measures, we also administered an end-of-class survey to get long-term student feedback. The following paragraphs describe both measures.

The measures we gathered during each class included: student preparation time, quiz scores, discussion participation rates, and in-class feedback. Student

October 20 - 23, 2004, Savannah, GA

\section{$34^{\text {th }}$ ASEE/IEEE Frontiers in Education Conference}


preparation time, the amount of time students spent preparing for the in-class case discussion or activity, was expected to approach two hours. This preparation usually involved reading and interacting with the materials before class. Other required student preparation involved analyzing interfaces or researching aspects of the topics. This selfreported measure was collected anonymously from each student. Professionally prepared case materials were closest to the ideal, involving an average of 67 minutes of student preparation time. On the other extreme, contemporary articles only resulted in an average of 33 minutes of student preparation.

To assess conceptual mastery supported by the various material types and to motivate student preparation efforts, a quiz was given at the beginning of each class activity. In comparing quiz scores, no material type facilitated consistently higher grades, but the familiar interfaces, professionally prepared cases, and ongoing development

\section{TABLE I}

COMPARING BENEFITS (+) AND DRAWBACKS (-) FOR EACH OF THE MATERIAL TYPES, ACCORDING TO SELECTED MEASURES. STARS SHOW THE STRONGEST BENEFITS, DOUBLE ' $X$ ' SHOW STRONGEST DRAWBACK. DASH INDICATES EQUALITY.

\begin{tabular}{|c|c|c|c|c|c|c|c|c|c|c|}
\hline & \multicolumn{2}{|c|}{$\begin{array}{l}\text { Contemporary } \\
\text { Article }\end{array}$} & \multicolumn{2}{|c|}{$\begin{array}{l}\text { Familiar } \\
\text { Interface }\end{array}$} & \multicolumn{2}{|c|}{$\begin{array}{l}\text { Professionally } \\
\text { Prepared Case }\end{array}$} & \multicolumn{2}{|c|}{$\begin{array}{c}\text { Ongoing } \\
\text { Development Project }\end{array}$} & \multicolumn{2}{|c|}{ Jigsaw } \\
\hline & + & - & + & - & + & - & + & - & + & - \\
\hline Student Preparation Time & & $\begin{array}{c}\text { varies } \\
\text { on method }\end{array}$ & & & & & & & & \\
\hline $\begin{array}{l}\text { Reported "Materials } \\
\text { Facilitated Preparation" }\end{array}$ & & & & & & & & & & \\
\hline Quiz Scores & & $\begin{array}{c}\text { varies } \\
\text { on method }\end{array}$ & & & & & & & & \\
\hline $\begin{array}{l}\text { Discussion Participation } \\
\text { Rates }\end{array}$ & & & & & & & & & & \\
\hline $\begin{array}{l}\text { Reported "Materials } \\
\text { Prepared to Participate" }\end{array}$ & & & & & & & & & & \\
\hline $\begin{array}{l}\text { Actual Long-term } \\
\text { Retention }\end{array}$ & & & & & & & & & & \\
\hline $\begin{array}{l}\text { Reported "Materials } \\
\text { Supported Retention" }\end{array}$ & & & & & & & & & & \\
\hline $\begin{array}{l}\text { Reported "Materials } \\
\text { Beneficial for Reference" }\end{array}$ & & & & & & & & & & \\
\hline In-class Feedback & & $\begin{array}{l}\text { varies } \\
\text { on method }\end{array}$ & & & & & & & & \\
\hline Long-term Feedback & & & & & & & & & & \\
\hline
\end{tabular}

project material types supported roughly average $(85 \%)$ student performance with low standard deviation. Quizzing concepts demonstrated by contemporary articles produced widely varying quiz scores; student performance seemed more dependent upon the type of case discussion for which they were preparing.

Student discussion participation rates were recorded for each of the class periods with case activities, capturing the number of students who gave a thoughtful contribution to the discussion. None of the material types produced a clearly higher participation rate, but the contemporary articles, familiar interfaces, and ongoing projects had high-average participation rates (78-100\%). Professionally prepared case materials had the lowest participation, with low-average rates (63-88\%).

Furthermore, students provided in-class feedback, voting whether specific materials supported understanding and ability to apply the topic. This was an immediate reaction to their experience in the activities, reflecting student confidence in the HCI skills they acquired. Professionally prepared and familiar interface case materials resulted in the most positive feedback, nearly all students agreeing that the materials supported both objectives. Contemporary articles received inconsistent ratings, probably driven by the actual case method rather than the material type.

Beyond the daily collection of immediate feedback, we also gathered student opinions related to case materials with an end-of-course survey. Because this was a six-week summer course, students were more likely to remember all activities conducted throughout the course than for a typical 15-week semester. Four questions paralleled the in-class measures reported above, to include a perception of whether materials supported case discussion preparation and participation, as well as retention of knowledge and ability to reference it later. 
From the five choices of material types, students most often selected professionally prepared case materials as best facilitating preparation efforts. The results were nearly identical for the material type that best prepared students for participation in case activities. Coupled with the fact that students spent more preparation time with the professionally prepared materials, we can infer that students saw value in their time spent. However, it is disappointing that this perceived value was not actualized with distinctive quiz performance, actual discussion participation, or in-class feedback. With the jigsaw, although students spent moderate preparation time, they almost never thought of this type as a material that prepared them well for case activities, reinforced by low quiz scores and only moderate in-class participation.

We were also interested in how well students retained knowledge of the case activities. The end-of-course survey asked students to recall the conceptual topic for each of the cases, given only a brief description of the activity as a cue. The familiar interfaces supported the highest actual retention rates $(71 \%)$. The least recalled topics were those addressed with the jigsaw technique (only 17\%). In addition to actual retention, we also measured the students' perceptions that the material types supported retention. Consistent with the actual retention, familiar interfaces had the highest perceived support for retention. None of the other types had positive ratings, and the jigsaw technique was the worst.

We were also interested in perceptions related to long-term benefits of case materials as references for students. About half of the students felt professionally prepared case materials would be best for reference, with the others selecting either contemporary articles or familiar interfaces as best. The jigsaw and ongoing development projects had the worst ratings. When asked about their opinion of the best activity in terms of educational value (long-term feedback), students most frequently selected cases based on familiar interfaces and ongoing development projects.

\section{INSTRUCTOR FACTORS}

Substantial support is required for instructors to successfully adopt the case method, evident through our own observations and experiences. Different material types imply different levels of support for quiz creation, instructor preparation time, necessity for high-level overviews, and techniques for relating case material to education topics. These are all important considerations in assessing material types that support the use of the case method.

One of the most important things the instructor can do to focus the students on learning and applying the methods and higher-level concepts is to create a quiz that both challenges the students, yet probes the important aspects of the material related to the topic at hand. However, to reward student preparation on specific case material, quizzes should 0-7803-7961-6/03/\$17.00 @ 2004 IEEE try to include both content questions (about the case material) as well as conceptual questions (about the topic to be covered). Each of the material types presents unique tradeoffs in quiz creation. The most difficult material types for creating "good" quizzes are contemporary articles and familiar interfaces. While it would be easy to find tiny details to test, the quizzes should address the underlying concepts, ideally providing an initial experience in applying them. Since many contemporary articles and familiar interfaces are crafted for different, non-instructional purposes, instructors must infer the underlying theories and methods. At the other extreme, professionally prepared case materials provide plentiful content and concept issues for quizzes, allowing quick creation of a quiz.

The amount of instructor preparation time also varies with the material type. Based on personal experience, professionally prepared case materials and contemporary articles took the most time to process. In contrast, familiar interfaces and ongoing projects require the least amount of reading and preparation time, due to the pre-existing familiarity with the material and the freedom for interpretation. An experienced instructor can infer underlying theories and methods from articles and interfaces on the fly, but all instructors must carefully read case materials to understand and relate the experiences of the authors.

Taking into account the challenges of creating a quiz and excessive instructor preparation time, high-level guides would be helpful for professionally prepared case materials This became apparent through use of the UCS library. Each case in the lbrary has at least 50 pages of materials. In addition, finding specific information is a challenging task even in this structured material, since there are limited navigation aides. A synopsis or guide for an instructor could reduce the amount of time required for familiarization with the material, although this adds further to the already formidable preparation effort for these materials.

\section{CONCLUSIONS}

By probing the question of material composition, this work facilitates adoption of the case method in HCI. Based on our results, we can make several conclusions that should influence selection and development of materials for casebased pedagogy:

- Best results in terms of in-class participation, student perception, and long-term retention come from use of familiar interfaces. This is not correlated to preparation time or expectation that preparation will result in participatory discussion. Both instructors and students might be uncomfortable with the lower than average preparation time required. However, as we found in our experiences, even a relatively inexperienced instructor can facilitate classroom activities with this type of material that are highly participatory, memorable, and earn strong student feedback.

October 20 - 23, 2004, Savannah, GA

\section{$34^{\text {th }}$ ASEE/IEEE Frontiers in Education Conference}


- Professionally prepared case studies compel students to engage in lengthy preparation time, although that does not appear to readily transfer to quiz performance, discussion participation, or long-term retention of key concepts. Perhaps a bit disturbingly, students do consider these to be the best source of reference. They may realize that, with the large volume of information that the case studies contain, the material provides answers to a wide variety of questions, though additional familiarity or mechanisms (e.g., improved interfaces, learner-imposed organization, and information indices) would be needed to unlock this knowledge. As an alternative, we can improve the perception of students relating to the usefulness of referencing material on familiar interfaces, since this type of material supported the most encouraging short term and long term learning outcomes. For instance, as part of the case activities, instructors could require creation of an archive relating the familiar interface to methodological or conceptual concerns.

- While promising, jigsaw materials need the most work. In this iteration, the jigsaw materials were perhaps the mo st discouraging approach to the case method, contrary to successes in other fields [5]. Based on the general goals within computer science education, we think that jigsaws represent an important exercise in assembling related information in order to understand a larger situation or problem. New techniques for jigsaw material creation and synthesis are needed. The techniques should allow individual students to become experts on a small facet and motivate assembly of information pieces without sacrificing appreciation of the big picture.

We can also offer several points for instructors that are considering use of the case method in HCI classes:

- In general, the use of the case methods supported high levels of class participation, enabled mastery of HCI concepts, and was well received by students. The use of realistic, tangible materials allowed students to connect abstract concepts and methods with actual design artifacts, gaining invaluable experience efficiently.

- Selection of material type had large impact on student preparation, discussion performance, and retention of learned concepts, as well as implications for instructor preparation. Instructors should consider the tradeoffs resulting from material type as they plan their approach to case method instruction.

- As instructors work to mitigate material related tradeoffs, particular attention should be devoted to preparation guides for case materials. Writing guides for case material that exist in other fields are not necessarily applicable to HCI topics and need careful review and extension.
As the case method becomes an increasingly more viable pedagogical approach for $\mathrm{HCI}$ education, future work must investigate techniques that amalgamate interface development processes with case material production efforts, a point also noted by [13], to enhance knowledge management among developers. Professional HCI activities that naturally include case generation processes can provide material that readily feeds into educational efforts. A key consideration within this challenge is structuring the case generation process so as not to create an additional burden for designers, yet to yield materials that are interesting and digestible for novice students. In this symbiotic development-education approach founded on case materials, the HCI field builds a more scientific basis within computer science education.

\section{REFERENCES}

[1] Akin, O. "Case-based instruction strategies in architecture." Design Studies 23 (2002), Elsevier Science, 407-431.

[2] Christiansen, C.R, and Hansen, A.J. Teaching and the Case Method, Harvard Business School, Boston, 1987.

[3] Ganoe, C., Somervell, J., Neale, D., Isenhour, P., Carroll, J. et al. "Classroom BRIDGE: using collaborative public and desktop timelines to support activity awareness." In Proceedings of Sixteenth Annual ACM Symposium on User Interface Software and Technology (UIST'03). November 25, 2003. Vancouver, British Columbia, Canada.

[4] Herreid, C.F. "Case studies in science: A novel method of science education." Journal of College Science Teaching 23 (2), February 1994, NSTA Publications, 221-229.

[5] Herreid, C.F. "Jigsaw: A Case Study Technique Where Students Become Experts." Originally from Journal of College Science Teaching, available: http://ublib.buffalo.edu/ libraries/projects/cases/teaching/jigsaw.html.

[6] Jones, J. "Participatory teaching methods in computer science." In Proceedings of the Eighteenth SIGCSE Technical Symposium on Computer Science Education (1987), ACM Press, 155-160.

[7] Kardos, G. "Engineering cases in the classroom." In Proceedings of the National Conference on Engineering Case Studies (1979), Available at http://www.civeng.carleton.ca/ECL/cclas.html

[8] Standridge, C. R. "Teaching simulation using case studies." In Proceedings of the 2000 Winter Simulation Conference, ACM Press, 1630-1634.

[9] Rosson, M.B. \& Carroll, J.M. "Case studies for teaching scenariobased usability engineering." Unpublished, available at http://java.cs.vt.edu/public/projects/cases/references/ documents/CCLIforJCSE.doc

[10] Wagner, I., Kompast, M., and Lainer, R. "Visualization Strategies for the Design of Interactive Navigable 3-D Worlds." interactions IX.5, September + October 2002, ACM Press, 2534.

[11] Whiddett, R.J., Handy, J.A., and Pastor, IL. "Cross-sectional case studies: Integrating case studies and projects in I.S. 
management education." In Proceedings of the Second Australasian Conference on Computer Science Education (1997), ACM Press, 52-58.

[12] Wilson, S., Bekker, M., Johnson, P, and Johnson, H. "Helping and Hindering User Involvement - A tale of Everyday Design." In Proceedings of the Conference on Human Factors in Computing Systems. March 1997, 22-27.

[13] Wixon, D. "Evaluating usability methods: Why the current literature fails the practitioner." interactions 10 (4), July 2003, ACM Press. 